\title{
A SYSTEMATIC REVIEW OF HEPATITIS VIRUS REVIEW STUDIES: A CASE OF HEALTH ECONOMIC EVALUATION ANALYSIS
}

\author{
PHUONG HONG LE, QUANG VINH TRAN, TRUNG QUANG VO
}

Department of Pharmacy Administration, Faculty of Pharmacy, University of Medicine and Pharmacy, Ho Chi Minh City 700000, Vietnam Email: voquangtrungdk@gmail.com

Received: 25 Jan 2017 Revised and Accepted: 20 Mar 2017

\section{ABSTRACT}

Objective: Systematic reviews of economic analysis are necessary for assessing reports and making a decision. A systematic review of systematic reviews is mean of summarizing the current evidence across specialties of the same or very similar intervention, to provide a synthesis treatment effect. The aim of this study was to explore and to assess the quality of systematic reviews conducted hepatitis economic evaluation.

Methods: This study was designed as a systematic review following the AMSTAR guideline through Medline, Cochrane, and Science Direct databases. It was scoped in publication period of 2001 and 2016 in international journals. The quality assessment of the included studies was based on AMSTAR checklist. Two authors did the appreciation independently and all the different results were solved by discussion to give the conclusion.

Results: 851 publications found, only 25 studies of those met the inclusion criteria. These studies consisted of 5 studies for vaccination and 20 for non-vaccination. There were only $16 \%(n=4)$ based on PRISMA guideline; and twenty-one studies $(64 \%)$ were not showing about the method of the systematic review or not based on any guideline. Only three articles has published in 2016 with a high standard.

Conclusion: According to the results of the appraisal AMSTAR checklist, this review shows clearly the current situation and an urgent need for an increase of quality of hepatitis virus review studies based on health economic evaluation.

Keywords: Economic analysis, Economic evaluation, Hepatitis, Literature review, Systematic review, Review

(C) 2017 The Authors. Published by Innovare Academic Sciences Pvt Ltd. This is an open access article under the CC BY license (http://creativecommons.org/licenses/by/4.0/) DOI: http://dx.doi.org/10.22159/ijpps.2017v9i5.17295

\section{INTRODUCTION}

Economic evaluation in health care studies has been more considerable and become a useful method for economists to improve the efficiency of the solution offered [1]. Researchers have appreciated the importance of giving an overview of individual studies to have a better quality and wider scope. They have assessed quantity or quality, summed up data of a group of records in comparable areas. As an effect, several systematic reviews of economics have been published in many international journals and they have been an essential part of the public policymaking process [1]. A systematic review of systematic reviews is a mean of summarizing the current evidence across specialties of the same or similar intervention, to provide a synthesis treatment effect [2, 3]. There are numerous reviews conducted, so it is difficult to access the information from these articles. A systematic review of reviews is a potential way to recap the details of the reviews. It permits readers to have a brief diverse ways such as comparison, contrast and provide clinical decision makers with the evidence they need [4].

Liver diseases have been regarded as a public health issue due to its effect on the patient body, finances of their family and society. Some kinds of them can be mentioned as hepatitis A virus (HAV) $[5,6]$ hepatitis B virus (HBV) [7-11], hepatitis C virus (HCV) [12-14], hepatitis D virus (HDV) [15], hepatitis E virus (HEV) [16,17], and liver cirrhosis [18]. Thanks to vaccination, people can be prevented from these physical problems and that could lead to reducing a number of infection cases. Presenting the relationship between cost of illness, cost-effectiveness, and stages of liver diseases are the reason why researchers carry out economic evaluation studies of hepatitis virus [19].

Participants of each research could be different, namely, the authors focused on an aspect of hepatitis. From the information of their articles, the readers could be able to appraise the efficacy of diagnoses, treatment methods or pharmaceutical products. To give more reliable evidence, many hepatitis economic evaluation reviews were published with various topics included in HAV [20], HBV [21], HCV [22], comparing between HBV and $\operatorname{HCV}[23,24]$, other liver diseases [25, 26], hepatitis vaccinations [28-30]. Of hepatitis economic evaluation, none of the authors designed their studies as a literature review of studies, and there is relatively small number of reviews of published economic evaluation reviews in other subjects at present, for examples, about vaccination [31], hormone therapy, chemotherapy, and targeted therapy for breast cancer [32], telemedicine [33]. The aim of this study was to explore general characteristics of a systematic review of hepatitis virus and its vaccination in health care economic evaluation.

\section{MATERIALS AND METHODS}

\section{Study design}

This study was conducted as a systematic review of economic evaluation reviews about liver diseases in several countries from 2001 to 2016. Two reviewers did the search so that reviews of hepatitis-virus-related economic evaluation were found. After that, filtering was carried out following pre-identified inclusion and exclusion criteria. The assessment was handled based on the piloted form that we had designed before to collect all the information that we needed and "A measurement tool to assess systematic reviews" tool (AMSTAR) to check the quality of each review. We recapped the results and had a discussion to give conclusions which help the future researchers will have a better standard review.

\section{Literature search}

This study was searched on Medline, Cochrane, and Science Direct databases to find articles published from 2001 to 2016 independently, then combined and discarded duplicates. The seeking target was to access to published or accepted review publications about the economic evaluation of hepatitis virus. The keywords, "hepatitis [MeSH terms]" and "economic evaluation [MeSH terms]" and "review [MeSH terms]" and "immunization [MeSH Terms]", were searched in "Title/Abstract" so as to limit a number of search results. 


\section{Selection criteria}

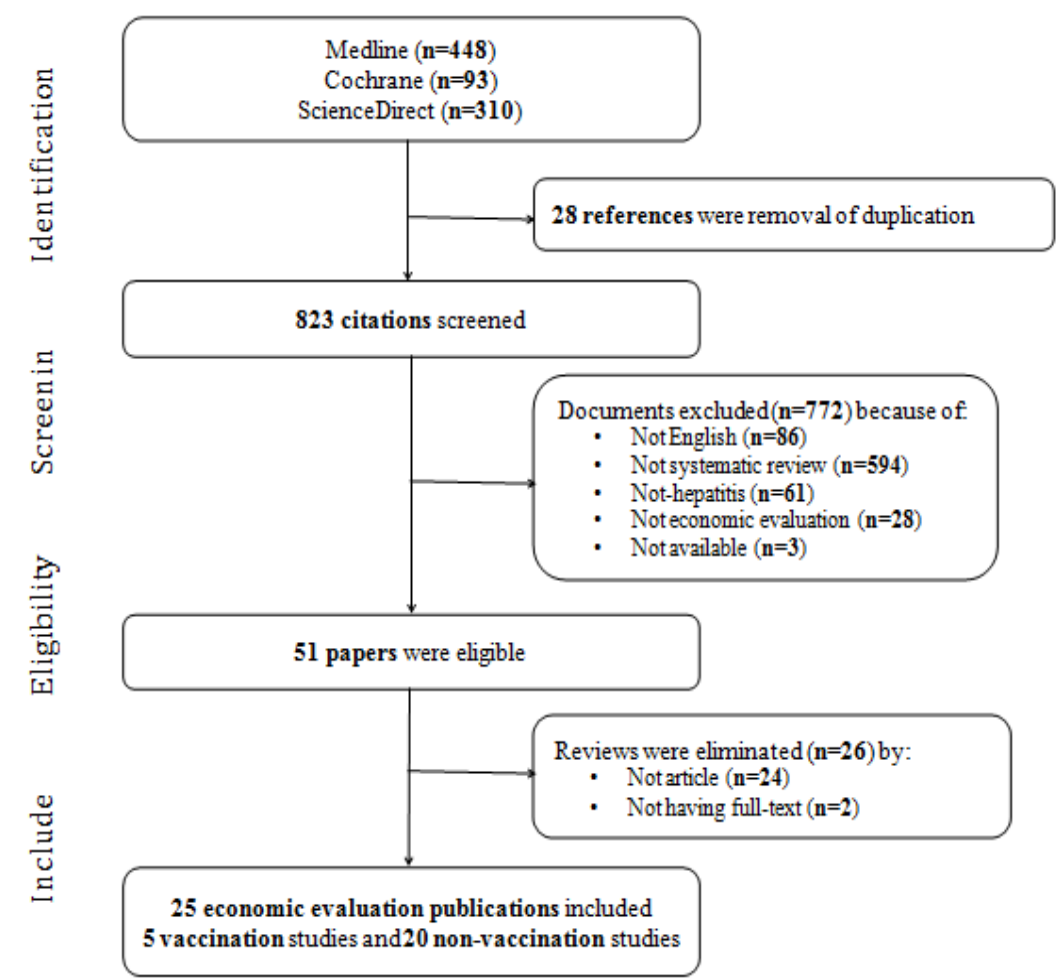

Fig. 1: Flow of information

Publications were chosen if they were literature or systematic reviews of economic evaluation articles which used primary data, with topics such as hepatitis virus, hepatitis virus vaccine or liver diseases. Studies were excluded due to being published in other languages, but not English or not relating to humanity. Conference abstracts or textbooks should be eliminated. When screening had finished, there were 25 publications retrieved (fig. 1)

\section{Data assessment}

More than 24 instruments were used for the quality evaluation of systematic reviews [34, 35] such as The Quality of Reporting of Meta-analyses (QUOROM) [34], Overview Quality Assessment Questionnaire (OQAQ) [34], a checklist designed by Sack [36], by Oxman and Guyatt [37], by Beverley J Shea [35], Preferred Reporting Items of Systematic reviews and Meta-analyses (PRISMA) [38] or Critical Appraisal Skills Programme (CASP) of systematic reviews [39] etc. In this study, AMSTAR tool was to have a summary of reviews of hepatitis virus economic evaluation. AMSTAR is a trustful method for documenting the standard of systematic reviews [40]. For appraising the quality of reviews in this studies, we discussed to give the conditions that the reviews should meet for each question in AMSTAR checklist. To understand the meaning of the AMSTAR question [35] clearly and how to score a review, we consulted correlative reports [35, 41-43].

Factors of the checklist focused on the estimation of databases authors used, inclusion and exclusion criteria, the quality of the included studies, publication bias and conflict of interest. In each AMSTAR question, there were four options such as 'yes' (question fulfilled), 'no' (question not performed), 'can't answer' (not enough information to answer the question) or 'not applicable' (question not met adequate conditions to tick 'yes'). If 'yes' category was chosen, item got '1 point'; if not, it had '0 points' [41].

Twenty-five publications were appraised with AMSTAR checklist by two authors independently and differences were solved based on persuasion to give the final decision. According to Mohammad 0 Sharif 's recommendation [41], 25 publications were divided into three following groups depending on its total points such as low quality (0-3), medium quality (4-7), and high quality (8-11).
Moreover, a table was created to collect the information concerned, for instance, the number of articles which concentrated on the vaccine, type of economic evaluation, the usage of some databases frequency and checklists.

\section{RESULTS}

The search collected 851 articles of hepatitis virus economic evaluation from 2001 to June 2016 consisted of 488 papers from Medline, 93 papers from Cochrane, and 310 papers from Science Direct. Twentyeight duplicated references were removed in the next stage. After screening based on inclusion and exclusion criteria with two stages consisted of their title/abstract and full-text, 25 studies were retrieved. They involved in five vaccination publications $[1,27,28,44,45]$ and 20 non-vaccination publications [12, 20-26, 46-57].

\section{General characteristics}

Eligible articles should be published from 2001 to 2016. We can see that the number of reviews researched rose dramatically. With only 3 studies between 2001 and 2005, but in the next five years (2006-2010), the quantity increased with eight articles and continued to reach the number of eleven. It is noticeable that in the first six months of 2016, the fig. was equal to the fig. from 2001 to 2005 . There were five vaccination studies included in two for $\operatorname{HAV}[1,27]$, three for HBV [28,44,45]. Among 20 non-vaccination studies, while HCV was conducted most with 10 reviews (40\%), an article solely mentioned HAV and five groups of authors carried out HBV publications. Other subjects were combining HBV and HCV [23], hepatocellular carcinoma [25], liver fibrosis, and cirrhosis $[26,46]$. Most of the reviews focused on the cost effectiveness of hepatitis virus, whilst the remaining cost analyses were referred very relatively (table 1).

There were only $16 \%(n=4)[12,23,24,44]$ based on PRISMA guideline. On the contrary, twenty-one studies (64\%) did not showing about the method of the systematic review or not based on any guideline. The number of publications reviewed in each included study fluctuated. Almost publications (72\%) chose 2 to 20 articles in order to have an overview. There were six studies that analyzed more than 20 publications. Especially, the quantity of Crossan et al., 2015's review/article [46] was observable with 
In general, there were approximately $50 \%(\mathrm{n}=12)$ with medium quality $[1,25-28,46,48,49,51,53,54,57]$. Eight studies $[12,21-24$, $44,45,52]$ which had 8 points or more gained high classification and five remaining studies $[20,47,50,55,56]$ were put at the low level. The results of appraisal described comprehensibly in table 3 . It is remarkable that all articles were published in 2016 [12, 26, 44] gained good quality. Therefore, we recognized current authors had been improving the standard of their studies.

Most of the articles met the requirement of item 6, and 7 (92-96\%). The number of publications lost points in the other questions fluctuated from 6 to15. Item 9 and 10 had the fewest studies that could be gained one point.

\section{DISCUSSION}

Currently, there are a couple of studies conducted with the same study design as ours, such as Trung Quang Vo et al. (2016) [31],
Vakaramoko Diaby et al. (2015) [32], Ekeland et al. (2010) [33]. There are some differences between these three studies and our research in the search strategy. Trung Quang Vo et al. (2016) retrieved concerned journals in only Medline with a combination of keywords and MeSH while Vakaramoko Diaby et al. (2015) used more databases (7 databases). It is Ekeland et al. (2010) that conducted the search in most databases (13 databases). Our searching was carried out in three, such as Medline, Cochrane, and Science Direct. It is noticeable all that these reviews of reviews searching in Medline.

In the standard of eligible studies assessment, Ekeland et al. (2010) used a revised checklist form Cochrane Effective Practice and Organization of Care Group (EPOC) to evaluate 13 cost-effectiveness publications and our study conducted with 25 hepatitis virus reviews.

Table 3: AMSTAR checklist results

\begin{tabular}{|c|c|c|c|c|c|c|c|c|c|c|c|c|}
\hline Eligible studies & Q1 & $\mathbf{Q 2}$ & Q3 & Q4 & Q5 & Q6 & Q7 & Q8 & Q9 & Q10 & Q11 & Total score \\
\hline De Soarez et al.[1] & 2 & 3 & 1 & 2 & 1 & 1 & 1 & 1 & 3 & 2 & 1 & 6 \\
\hline Luyten et al.[20] & 2 & 2 & 4 & 4 & 2 & 1 & 1 & 4 & 3 & 2 & 1 & 3 \\
\hline Anonychuk et al.[27] & 1 & 1 & 1 & 1 & 2 & 1 & 1 & 4 & 3 & 2 & 1 & 7 \\
\hline Crossan et al., 2015 [46] & 1 & 1 & 4 & 2 & 2 & 1 & 1 & 4 & 4 & 2 & 1 & 5 \\
\hline Hahne et al.[24] & 1 & 1 & 1 & 1 & 1 & 1 & 1 & 1 & 4 & 3 & 1 & 9 \\
\hline Buti et al.[21] & 1 & 1 & 1 & 1 & 1 & 1 & 1 & 4 & 1 & 3 & 1 & 9 \\
\hline Jones et al.[47] & 2 & 2 & 4 & 2 & 2 & 1 & 1 & 1 & 2 & 3 & 2 & 3 \\
\hline Sun et al.[48] & 1 & 1 & 1 & 4 & 1 & 1 & 1 & 4 & 3 & 3 & 2 & 6 \\
\hline Takeda et al.[49] & 2 & 1 & 1 & 1 & 1 & 1 & 1 & 4 & 3 & 4 & 1 & 7 \\
\hline Shepherd et al., 2006 [50] & 2 & 2 & 4 & 4 & 2 & 1 & 1 & 4 & 3 & 4 & 2 & 2 \\
\hline Beutels et al.[28] & 2 & 2 & 1 & 2 & 1 & 1 & 1 & 4 & 3 & 4 & 1 & 4 \\
\hline Smith-Palmer et al.[51] & 2 & 2 & 1 & 1 & 1 & 1 & 1 & 4 & 3 & 4 & 1 & 6 \\
\hline San Miguel et al.[52] & 2 & 1 & 1 & 1 & 1 & 1 & 1 & 1 & 3 & 3 & 1 & 8 \\
\hline John-Baptiste et al.[22] & 1 & 1 & 1 & 1 & 1 & 1 & 1 & 1 & 1 & 3 & 1 & 10 \\
\hline Tandon et al.[53] & 1 & 1 & 4 & 4 & 1 & 1 & 1 & 1 & 3 & 4 & 1 & 7 \\
\hline Hartwell et al.[54] & 1 & 1 & 1 & 4 & 2 & 1 & 1 & 4 & 4 & 2 & 2 & 5 \\
\hline Shepherd et al., 2007 [55] & 2 & 2 & 2 & 2 & 2 & 1 & 1 & 4 & 4 & 4 & 2 & 2 \\
\hline Shepherd et al., 2004 [56] & 2 & 2 & 4 & 4 & 2 & 4 & 1 & 4 & 3 & 2 & 2 & 1 \\
\hline Luhnen et al.[12] & 1 & 1 & 4 & 1 & 1 & 1 & 1 & 1 & 3 & 3 & 1 & 8 \\
\hline Geue et al.[23] & 1 & 1 & 1 & 1 & 1 & 1 & 1 & 4 & 1 & 3 & 1 & 9 \\
\hline La Torre et al.[44] & 1 & 2 & 1 & 1 & 1 & 1 & 1 & 4 & 1 & 3 & 1 & 8 \\
\hline Crossan et al., 2016 [26] & 2 & 2 & 1 & 1 & 2 & 1 & 1 & 4 & 3 & 4 & 1 & 5 \\
\hline Ruggeri et al.[25] & 2 & 2 & 4 & 1 & 1 & 1 & 1 & 1 & 4 & 2 & 1 & 6 \\
\hline Tu et al.[45] & 2 & 1 & 1 & 1 & 1 & 1 & 1 & 1 & 4 & 2 & 1 & 8 \\
\hline Shepherd et al., 2005 [57] & 1 & 1 & 4 & 1 & 2 & 4 & 1 & 1 & 4 & 4 & 1 & 5 \\
\hline
\end{tabular}

Trung Quang Vo et al. (2016), Vakaramoko Diaby et al. (2015) selected AMSTAR tools with the number of eligible studies were 11 and 10 , respectively, but Vakaramoko Diaby et al. (2015) edited the band score. The results of the appraisal were declared clearly in each review, Vakaramoko Diaby et al. (2015) divided the studies based on the assessment results, which is the same as our study, but the authors separated into two groups. They were fair scientific quality (score $=60 \%$ ), and good scientific quality (score $=70 \%$ or more). The highest modified AMSTAR score was $100 \%$.

Although there were not various systematic reviews of economic assessment reviews, most of them used AMSTAR checklist to appraise the standard of eligible publications. It proved that AMSTAR was a reliable instrument [40]. In general, none of the 25 articles we assessed got full of 11 AMSTAR scores due to a number of publications that did not meet the requirement to have full points in some questions. One-hundred percent of included articles did not evaluate publication bias clearly (item 10), and four studies used the methods to combine the findings of studies appropriately (item 9) (table 4). Before evaluating the quality of eligible studies by AMSTAR, two authors deliberated about various conditions for choosing "yes" in some items, such as in item 3, if the articles satisfied 4 in 5 factors below

- There were at least two sources should be searched.

- The report should express the period of time concerned.

- The report should include database used.

\section{- Keyword/MESH terms must be stated.}

- Searching should be supplemented by consulting current contents, reviews, textbooks, specialized registers, or experts in the particular field of study, and by reviewing the references in the studies found.

Almost studies met the first, the second and the third condition above $(84-88 \%)$.

For item 4, assessment result was "yes" if the author should state whether or not they excluded any reports based on language and publication.

In item 6, characteristics of the eligible studied must provide 4 in 6 items comprising of participants, interventions, comparisons, outcomes, study design, the other ranges of characteristics for example age, race, sex, relevant socioeconomic data, disease status, duration, severity, or other diseases. 
Table 4: The number of studies for each answer in items of AMSTAR checklist

\begin{tabular}{|c|c|c|c|c|c|c|c|c|c|}
\hline & \multirow[t]{2}{*}{ Questionnaire } & \multicolumn{2}{|c|}{ "Yes" } & \multicolumn{2}{|c|}{ “No" } & \multicolumn{2}{|c|}{$\begin{array}{l}\text { "Can't } \\
\text { answer" }\end{array}$} & \multicolumn{2}{|c|}{$\begin{array}{l}\text { "Not } \\
\text { applicable" }\end{array}$} \\
\hline & & $\mathbf{n}$ & $\%$ & $\mathbf{n}$ & $\%$ & $\mathbf{n}$ & $\%$ & $\mathbf{n}$ & $\%$ \\
\hline Q1 & Was a priori design provided? & 12 & 48 & 13 & 52 & - & - & - & - \\
\hline Q2 & Was there duplicate study selection and data extraction? & 14 & 56 & 10 & 40 & 1 & 4 & - & - \\
\hline Q3 & Was a comprehensive literature search performed? & 15 & 60 & 1 & 4 & - & - & 9 & 36 \\
\hline Q4 & Was the status of publication (i. e grey literature) used as an inclusion criterion? & 14 & 56 & 5 & 20 & - & - & 6 & 24 \\
\hline Q5 & Was a list of studies (included and excluded) provided? & 15 & 60 & 10 & 4 & - & - & - & - \\
\hline Q6 & Were the characteristics of the included studies provided? & 23 & 92 & - & - & - & - & 2 & 8 \\
\hline Q7 & Was the scientific quality of the included studies assessed and documented? & 24 & 96 & - & - & - & - & - & - \\
\hline Q8 & $\begin{array}{l}\text { Was the scientific quality of the included studies used appropriately in } \\
\text { formulating conclusions? }\end{array}$ & 10 & 40 & - & - & - & - & 15 & 60 \\
\hline Q9 & Were the methods used to combine the findings of studies appropriate? & 4 & 16 & 1 & 4 & 13 & 52 & 7 & 28 \\
\hline Q10 & Was the likelihood of publication bias assessed? & - & - & 8 & 32 & 9 & 36 & 8 & 32 \\
\hline Q11 & Was the conflict of interest included? & 19 & 76 & 5 & 20 & - & - & - & - \\
\hline
\end{tabular}

This study had some limitations such as the number of databases that we searched was much smaller than other systematic reviews of economic evaluation reviews as we stated. Moreover, our eligible criteria were the reviews published in English and conducted about liver-diseases-related economic evaluation, but we focused on HAV, $\mathrm{HBV}, \mathrm{HCV}$, and liver fibrosis whilst there are various liver diseases. There were also other reviews of hepatitis virus economic evaluation that our searching strategy could not find. In addition, it was possible that there were some mistakes in the results of studies.

\section{CONCLUSION}

At present, reviews of economic evaluation in the health care sector become better about not only quantity but also quality and they play an important role in supporting studies the improvement of the effectiveness of hepatitis virus diagnosis, treatment, and vaccination. According to our results, there is a lack of research about HCV immunization, combining hepatitis virus vaccinations, and that could be great topics for future reviewers. Moreover, we emphasize the importance of search strategy, the number of included journals, and usage of checklists for the reliability of results.

\section{ACKNOWLEDGEMENT}

The authors express their gratitude to all staffs at Professional Healthcare Management, Education and Research center (ProHES) and Assoc. Prof. Pham Dinh Luyen at Faculty of Pharmacy, University of Pharmacy and Medicine, Ho Chi Minh City for their supporting.

\section{AUTHOR CONTRIBUTION}

Phuong Hong Le, Quang Vinh Tran and Trung Quang Vo designed a methodology and conducted the search strategy. All three authors collected and appreciated the data. After that, Phuong Hong Le summarized and analyzed the outcome. Phuong Hong Le, Quang Vinh Tran and Trung Quang Vo wrote this paper and reviewed overall to concur with the final manuscript.

\section{CONFLICT OF INTERESTS}

There is no conflict of interest to declare

\section{REFERENCES}

1. De Soarez PC, Sartori AM, Santos A, Itria A, Novaes HM, Martelli CM. Contributions from the systematic review of economic evaluations: the case of childhood hepatitis A vaccination in Brazil. Cad Saude Publica 2012;28:211-28.

2. Bowater RJ, Stirling SA, Lilford RJ. Is antibiotic prophylaxis in surgery a generally effective intervention? Testing a generic hypothesis over a set of meta-analyses. Ann Surg 2009;249:551-6.

3. Bowater RJ, Abdelmalik SM, Lilford RJ. Efficacy of adjuvant chemotherapy after surgery when considered overall cancer types: a synthesis of meta-analyses. Ann Surg Oncol 2012; 19:3343-50.
4. Smith V, Devane D, Begley CM, Clarke M. Methodology in conducting a systematic review of systematic reviews of healthcare interventions. BMC Med Res Methodol 2011;11:15.

5. Aggarwal R, Goel A. Hepatitis A. Epidemiology in resource-poor countries. Curr Opin Infect Dis 2015;28:488-96.

6. Pham B, Duval B, De Serres G, Gilca V, Tricco AC, Ochnio J, et al. Seroprevalence of hepatitis an infection in a low endemicity country: a systematic review. BMC Infect Dis 2005; 5:56.

7. Anisyah Achmad RAF, Mustofa, Ayu Lestari Prihadi. The incidence of liver fibrosis based on non-invasive markers and hepatotoxic drug used in hepatitis B patients. Asian J Pharm Clin Res 2014;7:287-90.

8. Govindarao Kamala SV, K Naga Valli. Development and validation of rp-hplc method for simultaneous estimation of lamivudine and zidovudine in bulk. Int J Curr Pharm Res 2016;8:28-33.

9. Layek B, Lipp L, Singh J. APC targeted micelle for enhanced intradermal delivery of hepatitis B DNA vaccine. J Controlled Release 2015;207:143-53.

10. Bermingham SL, Hughes R, Fenu E, Sawyer LM, Boxall E, P TK, et al. Cost-effectiveness analysis of alternative antiviral strategies for the treatment of HBeAg-positive and HBeAgnegative chronic hepatitis $b$ in the united kingdom. Value Health 2015;18:800-9.

11. Jia Y, Li L, Cui F, Zhang D, Zhang G, Wang F, et al. Costeffectiveness analysis of a hepatitis B vaccination catch-up program among children in Shandong Province, China. Hum Vaccin Immunother 2014;10:2983-91.

12. Luhnen M, Waffenschmidt S, Gerber-Grote A, Hanke G. Health economic evaluations of sofosbuvir for the treatment of chronic hepatitis c: a systematic review. Appl Health Econ Health Policy 2016;14:527-43.

13. Llewellyn A, Faria R, Woods B, Simmonds M, Lomas J, Woolacott $\mathrm{N}$, et al. Daclatasvir for the Treatment of Chronic Hepatitis C: A Critique of the Clinical and Economic Evidence. Pharmacoeconomics 2016;34:981-92.

14. Wohl BM, Smith AAA, Jensen BEB, Zelikin AN. Macromolecular (pro)drugs with concurrent direct activity against the hepatitis $\mathrm{C}$ virus and inflammation. J Controlled Release 2014;196:197-207.

15. Niro GA, Smedile A, Fontana R, Olivero A, Ciancio A, Valvano $\mathrm{MR}$, et al. HBsAg kinetics in chronic hepatitis $\mathrm{D}$ during interferon therapy: on-treatment prediction of response. Aliment Pharmacol Ther 2016;44:620-8.

16. Adlhoch C, Avellon A, Baylis SA, Ciccaglione AR, Couturier E, de Sousa R, et al. Hepatitis E virus: assessment of the epidemiological situation in humans in Europe, 2014/15. J Clin Virol 2016;82:9-16.

17. Keya Chakrabarti KB, Karthik Rao N, Navin Patil, Avinash A, Talha Ahmed, George Varghese, et al. A study to assess the clinical and biochemical profile of patients diagnosed with hepatitis E in a large teaching hospital of southern india. Asian J Pharm Clin Res 2016;9:84-9. 
18. Thompson Coon J, Rogers G, Hewson P, Wright D, Anderson R, Jackson S, et al. Surveillance of cirrhosis for hepatocellular carcinoma: a cost-utility analysis. Br J Cancer 2008;98:1166-75.

19. Leidner AJ, Chesson HW, Xu F, Ward JW, Spradling PR, Holmberg SD. Cost-effectiveness of hepatitis C treatment for patients in early stages of liver disease. Hepatology 2015;61:1860-9.

20. Luyten J, Beutels P. Costing infectious disease outbreaks for economic evaluation: a review for hepatitis A. Pharmacoeconomics 2009;27:379-89.

21. Buti M, Oyaguez I, Lozano V, Casado MA. Cost-effectiveness of first-line oral antiviral therapies for chronic hepatitis B: a systematic review. Pharmacoeconomics 2013;31:63-75.

22. John-Baptiste A, Yeung MW, Leung V, van der Velde G, Krahn M. Cost-effectiveness of hepatitis C-related interventions targeting substance users and other high-risk groups: a systematic review. Pharmacoeconomics 2012;30:1015-34

23. Geue $\mathrm{C}, \mathrm{Wu} \mathrm{O}$, Xin Y, Heggie R, Hutchinson S, Martin NK, et al. Cost-Effectiveness of HBV and HCV screening strategies--a systematic review of existing modelling techniques. PLoS One 2015;10:e0145022.

24. Hahne SJ, Veldhuijzen IK, Wiessing L, Lim TA, Salminen M, Laar $M$. Infection with hepatitis $B$ and $C$ virus in Europe: a systematic review of prevalence and cost-effectiveness of screening. BMC Infect Dis 2013;13:181.

25. Ruggeri M. Hepatocellular carcinoma: cost-effectiveness of screening. A systematic review. J Risk Management and Healthcare Policy 2012;5:49-54.

26. Crossan C, Tsochatzis EA, Longworth L, Gurusamy K, Papastergiou V, Thalassinos E, et al. Cost-effectiveness of noninvasive liver fibrosis tests for treatment decisions in patients with chronic hepatitis B in the UK: a systematic review and economic evaluation. J Viral Hepat 2016;23:139-49.

27. Anonychuk AM, Tricco AC, Bauch CT, Pham B, Gilca V, Duval B, et al. Cost-effectiveness analyses of hepatitis a vaccine: a systematic review to explore the effect of methodological quality on the economic attractiveness of vaccination strategies. Pharmacoeconomics 2008;26:17-32.

28. Beutels P. Economic evaluations of hepatitis B immunization: a global review of recent studies (1994-2000). Health Econ 2001;10:751-74.

29. Malewezi B, Omer SB, Mwagomba B, Araru T. Protecting health workers from nosocomial hepatitis $B$ infections: a review of strategies and challenges for implementation of Hepatitis B vaccination among health workers in Sub-Saharan Africa. Epidemiol Global Health 2016;6:229-41.

30. Rich JD, Ching CG, Lally MA, Gaitanis MM, Schwartzapfel B, Charuvastra A, et al. A review of the case for hepatitis B vaccination of high-risk adults. Am J Med 2003;114:316-8.

31. Trung Quang Vo AR. A literature review of health economics evaluation: a case of vaccination on systematic review analysis. J Appl Pharm Sci 2016;6:124-30.

32. Diaby V, Tawk R, Sanogo V, Xiao H, Montero AJ. A review of systematic reviews of the cost-effectiveness of hormone therapy, chemotherapy, and targeted therapy for breast cancer. Breast Cancer Res Treat 2015;151:27-40.

33. Ekeland AG, Bowes A, Flottorp S. Effectiveness of telemedicine: a systematic review of reviews. Int J Med Inform 2010;79:736-71.

34. Shea B DC, Moher D. Assessing the quality of reports of systematic reviews: the QUOROM statement compared to other tools. In: Systematic Reviews in Health Care: Meta-analysis in context. Edited by: Egger M, Smith GD, Altman DG. London: BMJ books 2001;7:122-39.

35. Shea BJ GJ, Wells GA, Boers M, Andersson N, Hamel C, Porter AC, et al. Development of AMSTAR: a measurement tool to assess the methodological quality of systematic reviews. BMC Med Res Methodol 2007;7:10.

36. Sacks HS, Berrier J, Reitman D, Ancona-Berk VA, Chalmers TC Meta-analyses of randomized controlled trials. N Engl J Med 1987;316:450-5.

37. Oxman AD. Checklists for review articles. Br Med J 1994; 309:648-51.
38. Moher D, Liberati A, Tetzlaff J, Altman DG. Preferred reporting items for systematic reviews and meta-analyses: the PRISMA statement. PLoS Med 2009;6:e1000097.

39. Crowe M, Sheppard L. A review of critical appraisal tools show they lack rigor: alternative tool structure is proposed. J Clin Epidemiol 2011;64:79-89.

40. Shea BJ HC, Wells GA, Bouter LM, Kristjansson E, Grimshaw J, Henry DA, et al. AMSTAR is a reliable and valid measurement tool to assess the methodological quality of systematic reviews. J Clin Epidemiol 2009;62:1013-20.

41. Sharif MO, Janjua-Sharif FN, Ali H, Ahmed F. Systematic reviews explained: AMSTAR-how to tell the good from the bad and the ugly. Oral Health Dent Manag 2013;12:9-16.

42. Sequeira-Byron P, Fedorowicz Z, Jagannath VA, Sharif MO. An AMSTAR assessment of the methodological quality of systematic reviews of oral healthcare interventions published in the Journal of Applied Oral Science (JAOS). J Appl Oral Sci 2011;19:440-7

43. Faggion CM Jr. Critical appraisal of AMSTAR: challenges, limitations, and potential solutions from the perspective of an assessor. BMC Med Res Methodol 2015;15:63.

44. La Torre G, Mannocci A, Saulle R, Colamesta V, Meggiolaro A, Mipatrini D, et al. Economic evaluation of HBV vaccination: a systematic review of recent publications (2000-2013). Hum Vaccines Immunother 2016;12:2299-31.

45. Tu HA, Woerdenbag HJ, Kane S, Riewpaiboon A, van Hulst M, Postma MJ. Economic evaluations of hepatitis B vaccination for developing countries. Expert Rev Vaccines 2009;8:907-20.

46. Crossan C, Tsochatzis EA, Longworth L, Gurusamy K, Davidson $\mathrm{B}$, Rodriguez-Peralvarez M, et al. Cost-effectiveness of noninvasive methods for assessment and monitoring of liver fibrosis and cirrhosis in patients with chronic liver disease: a systematic review and economic evaluation. Health Technol Assessment 2015;19:1-409.

47. Jones J, Shepherd J, Baxter L, Gospodarevskaya E, Hartwell D, Harris P, et al. Adefovir dipivoxil and pegylated interferon alpha for the treatment of chronic hepatitis B: an updated systematic review and economic evaluation. Health Technol Assessment 2009;13:1-172.

48. Sun X, Qin WX, Li YP, Jiang XH. Comparative cost-effectiveness of antiviral therapies in patients with chronic hepatitis B: a systematic review of the economic evidence. J Gastroenterol Hepatol 2007;22:1369-77.

49. Takeda A, Jones J, Shepherd J, Davidson P, Price A. A systematic review and economic evaluation of adefovir dipivoxil and pegylated interferon-alpha-2a for the treatment of chronic hepatitis B. J Viral Hepat 2007;14:75-88.

50. Shepherd J, Jones J, Takeda A, Davidson P, Price A. Adefovir dipivoxil and pegylated interferon alfa-2a for the treatment of chronic hepatitis B: a systematic review and economic evaluation. Health Technol Assessment 2006;10:iii-iv, xi-xiv, 1-183.

51. Smith-Palmer J, Cerri K, Valentine W. Achieving sustained virologic response in hepatitis $C$ : a systematic review of the clinical, economic and quality of life benefits. BMC Infect Dis 2015;15:19.

52. San Miguel R, Gimeno-Ballester V, Mar J. Cost-effectiveness of protease inhibitor-based regimens for chronic hepatitis C: a systematic review of published literature. Expert Rev Pharmacoeconomics Outcomes Res 2014;14:387-402.

53. Tandon P, Doucette K, Fassbender K, Vandermeer B, Durec T, Dryden DM. Granulocyte colony-stimulating factor for hepatitis C therapy-associated neutropenia: a systematic review and economic evaluation. J Viral Hepat 2011;18:e381-93.

54. Hartwell D, Jones J, Baxter L, Shepherd J. Peginterferon alfa and ribavirin for chronic hepatitis $\mathrm{C}$ in patients eligible for shortened treatment, re-treatment or in HCV/HIV co-infection: a systematic review and economic evaluation. Health Technol Assessment 2011;15:i-xii, 1-210.

55. Shepherd J, Jones J, Hartwell D, Davidson P, Price A, Waugh N. Interferon alpha (pegylated and non-pegylated) and ribavirin for the treatment of mild chronic hepatitis C: a systematic review and economic evaluation. Health Technol Assessment 2007;11:1-205. 
56. Shepherd J, Brodin H, Cave C, Waugh N, Price A, Gabbay J. Pegylated interferon alpha-2a and-2b in combination with ribavirin in the treatment of chronic hepatitis C: a systematic review and economic evaluation. Health Technol Assessment 2004;8:iii-iv, 1-125.

57. Shepherd J, Brodin HF, Cave CB, Waugh NR, Price A, Gabbay J. Clinical and cost-effectiveness of pegylated interferon alfa in the treatment of chronic hepatitis C: a systematic review and economic evaluation. Int $\mathrm{J}$ Technol Assess Health Care 2005;21:47-54.

\section{How to cite this article}

- Phuong Hong Le, Quang Vinh Tran, Trung Quang Vo. A systematic review of hepatitis virus review studies: a case of health economic evaluation analysis. Int J Pharm Pharm Sci 2017;9(5):114-120. 